\title{
Research on Physical System By Information Technology
}

\author{
Bin Wei \\ Hubei University Of Technology Engineering And Technology College, Wuhan 430068,China \\ weibin@163.com
}

Keywords: Physical education quality, Course construction in universities, Innovation method, Physical training

\begin{abstract}
The objective of this thesis is to provide both theoretical and empirical evidence for the further reform and development of the teaching quality of the undergraduate P. E. majors in the 21 century in order to deal with the confusing problems brought about by the conflict between the expansion and quality improvement; meanwhile, the establishment of teaching quality system and the proposal for the basic guidance is conducive to the smooth and sustainable development of the undergraduate P E. majors in this era of higher education being popularized.
\end{abstract}

\section{Introduction}

Since 1999, higher education in China has been expanded to meet the demands of the development of the socialist marketing economy, the popularization of higher education, the improvement of people's living standards and the stability and development of universities and colleges themselves, which enabled the higher education in China to achieve unprecedented success in 2002. Teaching quality is closely connected with the survival and development of universities and colleges because it determines both the cultivating quality and competitive ability of graduates, and it plays an extremely important role in the future development of universities and colleges. Thus it is no exaggeration to say that it is a matter of life and death to higher education in China. At present, as far as the undergraduate P.E. major is concerned, one of the serious problems of major reform and development lies in the conflict between the expansion and the quality improvement, namely, in this era of higher education being popularized, how to ensure and improve the teaching quality has become one of the thorniest problems confronting the teaching reform and development of the undergraduate PE. Major [1].

The reforms of PE teaching methods are more and more emphasis on the combination of educational theory and practice, and tend one fold to the comprehensive. Innovative education is an extension, ecpand and deepens of the quality education; it is an important way of cultivating high-quality creative talents [2]. Based on the study of PE teaching methods with the innovative education concept, not only can promote PE teachers to update their concepts, to change their roles, and to improve teaching quality and efficiency, but also can create a learning environment for students' independent thinking, the courage to explore, constant innovation, to help students master learning methods, to form a correct attitude and PE values. It aims to provide a reference for promoting the theoretical research of school PE, for enriching and innovating the modern PE teaching [3].

Compared to the concepts tended to describe the physical state such as "physique" and "physical strength" is a concept to describe the physical ability, which is used to describe the ability to finish an action or movement under the interaction of innate genetic and acquired circumstances, and it has been widely applied to the sports field as an important indicator to describe ability and quality of the athletes [4]. When describing the athletes' body function, physical fitness means the basic motor skills of the athletes' own body. Therefore, physical fitness is both an important part of athlete physical ability and the comprehensive ability for physical exercise to create excellent results the athletes must have. In general, physical fitness includes body shape, body function and athletic quality. Among them, the body shape means the inside and outside forms of the human body; body function is the function of various organs in the body; athletic quality is the various basic motor skills shown during sports activities. Among these three factors, body shape and body function are the material basis of 
physical fitness, while athletic quality is the external manifestation of physical fitness as well as the core of the physical performances [5]. The three ones are mutual separate, interrelated and restricted, and impact the level of the physical fitness as a whole. The specific relationships are shown in Figure 1.

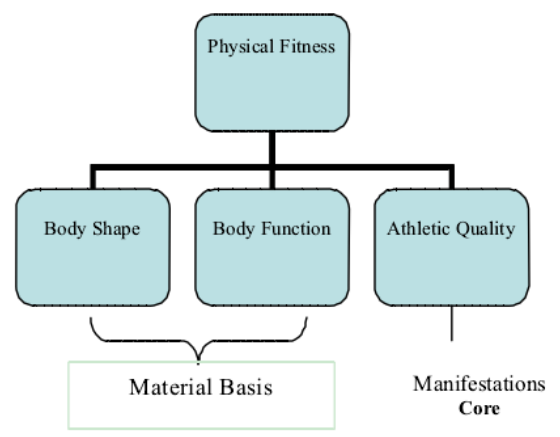

Fig. 1 The elements of fitness

\section{The Basic Problem and Influencing Factors in PE Education}

With the development of social economy, the differentiation of vocations and the increasing demands on technical content and professional level, a large number of high-level professionals are needed. In order to meet the demand, more and more students for professional master degree are admitted. It becomes an important task for current graduate education to cultivate high-level applied talents in China. Mater of Sport is a professional degree which has an objective to cultivate high-level talents in sport. Under augmentation of the enrollment scale of the professional graduate education, guarantee the teaching quality has significant meaning in promoting the development of professional graduate education with a well and quickly rapid. Methods in this paper include literature, expert interviews, and methods of logical analysis on the existing traditional teaching methods, tools, content, and organizing form analysis to make proposals to reform of current College Physical Education.

Detailed analysis of physical education curriculum in the past has shown a lot of problems.

(1) Teaching materials are out of date with sports knowledge, skills, and skills failing to meet the needs of modern society development.

(2) The lack of flexible teaching methods and means, teaching methods and means without normative and unity among teachers.

(3) Physical form of organization is too rigid. Students desire a flexible, autonomous forms of learning, elective courses, lectures, clubs, sports associations, viewing, and entertainment.

(4) PE organizational florins still remain in the beginning of the preparatory part of the basic part of the end of the rigid organization process; students' passive learning cannot maximize the mobilization of the enthusiasm of the students.

(5) Physical education ignores the after-school learning, the role of exercise to improve their physique and health, physical fitness, the ability to fight disease, the habit of exercise and the formation of the concept of lifelong sports.

Sport is not a simple exercise. It implies a lot of cultural elements. Traditional physical education rarely involved in cultural content, so it is difficult for students to have a strong interest in sports. Advanced science and technology of modern sports is increasingly being applied to sports. Pluralistic knowledge and multi-media are still very lacking in the physical education curriculum failing to meet the students' desire for knowledge.

The development of modern sports makes the new knowledge, new emerging and constantly updated knowledge of the structure. It has enabled teachers to keep abreast of the latest knowledge and mastery of new knowledge. It is an important prerequisite to improve the quality of physical education curriculum. Exchanges between teachers and students contribute to the teaching innovation. It is an important way to improve teaching efficiency and teaching quality. 
Traditional physical education evaluation is a one-sided assessment of students, skills without the assessment of students' actual tactics, exercise habits, sports consciousness, and the spirit of cooperation, the measure of emotional communication and social development of these non-intellectual factors. Cultivation of lifelong physical awareness, team spirit of cooperation is the most important goal of sports teaching content.

Evaluation of traditional physical education ignores the process of teaching, students' learning capabilities, organizational capabilities, self-management capabilities, exercise, physical capabilities, health awareness, and self-regulating capabilities. It cannot give full play to the sports learning evaluation, diagnostic, incentive, feedback, educational and other functions.

\section{The Innovation Method and Suggestions in PE Education}

Course construction is to gather high-quality educational resources and improve the quality of teaching so that students can get the best education and a greater range of teaching shared teaching activities. Its goal is to cultivate high-quality personnel needs of the community. April 8, 2003, the Ministry of Education released The Notice on the Start of the Teaching Quality and Teaching Reform Project Course Construction requiring the establishment of various categories of professional school, provincial and national levels, and quality curriculum system. The construction content includes: the discipline of planning, teaching team building, teaching contents and curriculum system, teaching methods and means of construction, construction of teaching materials and practice teaching bases, etc.

This training method means keeping stability strength training for the athletes in a relatively long period of time. During the training, the physical load of athletes should be strictly controlled to ensure the continuous training process. This method is also commonly used in physical training, and it can effectively enhance the athlete's endurance and stamina. Generally, there are three common ways of these training methods: continuous training method, alternating training method and Fatelaike training method. The specific training methods are shown in Table 1.

Table 1 Commonly used continued training method

\begin{tabular}{|l|l|}
\hline Training Methods & \multicolumn{1}{|c|}{ Patterns } \\
\hline $\begin{array}{l}\text { Continuous } \\
\text { Training Method }\end{array}$ & $\begin{array}{l}\text { In the context of aerobic training, maintain a } \\
\text { constant speed to make continuous training }\end{array}$ \\
\hline $\begin{array}{l}\text { Alternate } \\
\text { Training Method }\end{array}$ & $\begin{array}{l}\text { Rigorously practice time control to alternate a } \\
\text { number of training }\end{array}$ \\
\hline $\begin{array}{l}\text { Fatelaike } \\
\text { Training method }\end{array}$ & $\begin{array}{l}\text { It is a typical off-road type training method. } \\
\text { Depending on the field training terrain, adjust } \\
\text { training speed and load with a sense of } \\
\text { movement, and develop the aerobic endurance, } \\
\text { anaerobic endurance, and specialist endurance of } \\
\text { the athletes with purpose. }\end{array}$ \\
\hline
\end{tabular}

PE Course is an important part of Higher Education and an important way of full implementation of quality education and comprehensive development of talent. To carry out the construction of university sports programs promotes students' physical and mental health, strong-willed and all-round development. Students' health, mental health and social adaptation capabilities are related to personal growth and success, improvement of national health, and the construction of the major sports power and human resources power.

The general requirements are: to strengthen and improve the Physical Education Course Construction, adhere to the "healthy" school education, the guiding ideology, taking the construction of physical education curriculum as an important part of higher education to establish and improve PE Course of leadership mechanism, working mechanisms and accountability mechanisms to protect the full open good sports curriculum and improve teaching standards, to carry out a variety of extracurricular sports activities and competition, strengthen the construction of sports teachers, establish and improve the sports facilities, culture awareness, habits and capabilities of Lifelong Sport. 
The main principles of curriculum construction include: (1) through curriculum development to meet the needs of students' development; (2) through the development of courses to improve teachers' awareness of curriculum; (3) through curriculum development to form characteristics of local schools. With the development of physical education reform and sports workers' continuous exploration and research, it has become the inevitable trend of development of sports in the schools today to develop the concept of lifelong physical ability of sports. We cannot simply categorize sports teaching as teaching of sports knowledge and skills, and it is more important to have a scientific sports training methods and sports knowledge and sports consciousness.

The main initiatives of PE Courses include: (1) update the course content, modify the development of curricula, the preparation of teaching materials and handouts; (2) standardize teaching methods, teaching procedures; flexible, rich in the form of class organization; (3) grade teaching and individualized; (4) the use of multimedia courseware, to enrich the teaching methods, broaden the teaching time and space, and improve teaching efficiency; (5) establish the physical education curriculum website to make it become an important access to information and communication platform; (6) open sports cultural appreciation courses electives; (7) the establishment of sports clubs to enrich students' extracurricular lives.

\section{Conclusions}

The construction of physical education curriculum should be an effective teaching content, teaching methods and means of teaching organizational form to update and improve the course informative, interesting of sport courses making it a favorite of students. Combination of physical education and curriculum construction with sports culture and sports technology makes sports clubs as an extension of the physical education curriculum for further consolidating and improving the fun of sports to develop exercise habits and laying the foundation for lifelong physical education. Course construction is a long-term unremitting work, which aims to change teaching concepts, teaching and research, update the content of teaching, and to improve teaching methods and means to make our courses to fit the demand of social development and student knowledge to make more efficient and practical application of the value of teaching and learning activities. The launching of the course construction must be built on the basis of extensive research, with a strong feasibility of plans. Course construction is related to systems engineering of all teachers of a subject or a project, which requires every teacher to fully be engaged. In curriculum construction, establishing teaching concept and goal has a very important role, because it is the guidance of the work. Good ideas and goals are often able to guide our curriculum development to achieve good results.

\section{Acknowledgements}

From the Teaching Research Fund Subject in North China Institute of Science and Technology, Subject Number HKJYZD 201245

\section{References}

[1] G. Srikanthan\&John FDalrymple. Developing a Holistic Model for Quality in Higher Education. Quality in Higher Education, 2002, 8 ( 3 ) : 215-218.

[2] Parri, J. Quality in Higher Education. VA-DY BA/Mangement, 2006, 2(11): 107-111.

[3] Neave, Cx Higher Education in a Period of Consolidation: 1975-1985. European Journal of Education, 1985: 109-111.

[4] Martin Trow. Problems in the Transition from Elite to Mass Higher Education. Policies for Higher Education-General Report of the Conference on the Future Structure of Post-secondary Education. OECD, 1974. 
[5] Patricia J Gumport, Maria Iannozzi, Susan Shaman and Robert Zemsky Trends in Higher Education from Massification to Post-MassificaCion. International Seminar Reports, 1997. (10): 10-15. 